\title{
Parkinson gaixotasunaren biomarkatzaile klinikoen paperaren azterketa, ikuspegi epidemiologiko batetik
}

\section{A study of Parkinson's Disesase's clinical biomarkers from epidemiological view}

\author{
Haizea Ribera Sorazu ${ }^{1}$, Javier Ruiz Martínez ${ }^{1,2}$, Vicente Olasagasti Calzacorta ${ }^{1}$. \\ ${ }^{1}$ Donostiako Unibertsitate Ospitale, Neurologia zerbitzua \\ ${ }^{2}$ Biodonostia, Neurozientzien Area, Gaixotasun Neurodegeneratiboen Taldea
}

haizearibera@gmail.com

\section{Laburpena}

Parkinson gaixotasuna (PG), mugimenduen nahasmenduekin erlazionatutako gaixotasun neurodegeneratibo bat da. Populazio totalaren prebalentzia \% 0,1-0,3 inguruan dago eta haren etiologia ez da guztiz ezaguna oraindik. Nahiz eta klasikoki gaixotasun motor bezala definitu izan den, badaude gaixotasunaren hasierako faseetan presente egon ohi diren zenbait sintoma ez motor (SEM) gaixoen \%90ean. Horien artean daude nahaste disautonomikoak, sintoma sentsorialak eta emozionalak, eta lo-nahasmenduak. Sintoma horiek goiz agertzen direnez, garrantzitsuak dira biomarkatzale klinikoak bilakatu daitezkeelako. Forma genetikoak PGaren kasuen \% 15 dira eta ideia horren inguruan 2004. urtean LRRK2 genearen lehen mutazioa aurkitu zen, orain arte gaixotasuna garatzeko arriskua areagotzen duen faktore genetiko garrantzitsuena. Mutazio horietako bat euskal jatorriko biztanleen artean ohikoa zela ohartu ziren. Testuinguru horretan, gaixotasunaren prebalentzia jakin nahian, ikerketa epidemiologiko bat egin zen Azkoitian eta Azpeitian. Prebalentziaz gain, beste zenbait aldagairen artean, biomarkatzaile horien maiztasuna ere aztertu zen. Lagin berbera hamar urte pasa ondoren aztertzea interesgarria litzateke, adina, SEMen agerpena edota ingurumen-faktoreen garrantzia ikertzeko. Medikuntzako Gradu Amaierako Lana izan den ikerketa honetan, 2009an parte hartu zuten 232 pertsonetatik, 173ren informazioa jaso ahal izan da. Emaitzek diotenez, adinarekin bat, PGaren kasuen gorakada egon da. Gainera, REM loaren jokabidealterazioak (TCSR/REMJA) etorkizunean PGa garatzeko arriskua iragar lezakeen biomarkatzaile nagusia direla ikusi da. Emaitza hauek guztiak lanak dituen mugekin aztertu behar dira, laginaren tamaina txikia baita.

Gako-hitzak: parkinson gaixotasuna, REM loaren jokabide-alterazioak, sintoma motorrak, sintoma ez motorrak, traumatismo kraneoentzefalikoa

\section{Abstract}

Parkinson's Disease (PD) is a movement-related neurodegenerative disorder. The overall prevalence of $P D$ in the total population is around $0,1-0,3 \%$ and its etiology is hitherto unknown. Even if the disease has classically been defined as a pure motor movement disorder, non-motor symptoms (NMS), such as disautonomic, sensorial, emotional and sleeping disturbances, are also frequent in the earliest stages of the disease. Due to their early presentation, these NMS may serve as useful clinical biomarkers. Genetic forms are responsible of $15 \%$ of PD cases. Missense mutations in LRRK2 were first identified as a cause of $P D$ in 2004 and nowadays are known to be the main factor in 
contributing to the genetic development of PD. One of these mutations seemed to be especially frequent in population of Basque ascent. With the aim of assessing the disease prevalence in the area, an epidemiological study was conducted in 2009 within the communities of Azkoitia and Azpeitia. Not only was the prevalence studied but also the appearance of NMS as possible biomarkers of PD was analyzed. Based on this, we thought that it would be interesting to study the same population sample that was previously analyzed in 2009, 10 years after. The purpose was to determine the relevance of age, NMS and environmental factors on PD development. In the conducted research, out of the whole sample studied in 2009 (232), information about 173 individuals was found. According to the results, there was an increment of PD along with the increase of the sample's average age. Besides, the REM sleep behaviour disorder appears to be the most significant clinical biomarker of PD as well as the most meaningful risk factor to develop PD in the near future. All these outcomes need to be treated with some caution due to the reduced size of the sample analyzed.

Keywords: Parkinson's Disease, REM sleep behaviour disorder, motor-symptoms, Non-motor symptoms, Acute traumatic brain injury.

Bidalia: 2020ko urtarrilaren 7an

Onartua: 2020 apirilaren 15ean

http://doi.org/10.26876/osagaiz.1.2020.

\section{Sarrera}

Parkinson gaixotasuna (PG), maiztasunean, munduko bigarren neuroendekapen-gaixotasun ohikoena da, Alzheimer gaixotasunaren atzetik. Sindrome hau, James Parkinsonek deskribatu zuen lehenengoz, 1817. urtean, zeinek urte batzuen ostean, alfa-sinukleinaren metaketa patologikoarekin erlazionatu zen gaixotasun baten lehen kasuak deskribatu zituen. Material horren pilaketaren ondorioz, aktibitate motorra erregulatzeaz arduratzen diren mesentzefaloko substantzia beltzeko (SBC) neurona dopaminergikoen endekapen progresiboa sortzen da (1) (1. Irudia) (2). Braak eta kolaboratzaileek (2004), Lewy gorputzen agerpena deskribatu zuten nerbio-sistemako hainbat kokapenetan, eta gaixotasunaren garapenaren estadio ezberdinak proposatu zituzten. Agregatu horien garapena nerbio-sistema enterikoan has litekeela pentsatu eta adierazi zuten ikertzaile horiek, zehazki Auerbachen plexu mienterikoan. Teoria horren arabera, metaketa horiek, sistema enterikotik nerbio-sistema zentralera (NSZ) zabalduko lirateke, nerbio bagoaren bideari jarraituz. Neuroendekapen-prozesu horretan, sei estadio ezarri zituzten, usaimen-erraboiletik eta garunenborraren erraboil eta zubiko ataletatik hasi, besteak beste, bagoaren nukleo motor, locus caeruleusetik eta errafeko beheko nukleoetatik (1. eta 2. estadioak), eta hortik SBc-ra eta beste mesentzefalo eta prosentzefaloko nukleoetara (3. eta 4.estadioak) zabalduz. Azken kokapen horietako metaketak sintoma motorren (SM) agerpena eragiten du. Ondoren, agregatuak harago zabaldu eta neokortexera iristean (5. eta 6 . estadioak) gaixotasuna bere dimentsio kliniko osoan azaltzen da $(1,3)$.

Aipatutako teoria horrek, SEMen agerpena ez ezik, SMen aurretiko agerpena ere azalduko luke $(1,3)$.

PGaren sintoma bereizgarri gisa honakoak agertzen dira: atsedeneko dardara, bradizinesia, edo hortzdun gurpil erako zurruntasuna, eta postura eta ibileraren nahasmenak (1. taula). Sintoma horiei lotuta agertzen diren beste zenbait zeinuren artean ditugu mikrografia, hipofonia, aurpegi-hipomimia eta ibileraren izozte fenomenoa. Atsedeneko dardara asimetrikoa eta lehenengo agertzen den sintoma izan ohi da (\% 70-90), gazteetan batez ere. Bradizinesia, aldiz, gaixoak gehien ezgaitzen dituen sintoma izateaz gain, gazteetan baino adineko pazienteetan da ohikoagoa. Hala ere, gaixotasunaren hainbat eratan azaldu ohi da pazientearen arabera, eta zenbaitetan, sintoma horiek oharkabez pasatzen dira urteetan zehar (4). Badaude, hain ezagun ez izan arren, gaixotasun horretan agertzen diren SEM batzuk. Horien artean daude loaren nahasteak (bereziki TCSR), disfuntzio autonomikoa, hipotentsio ortostatikoa, idorreria, nahaste urogenitalak, antsietatea eta sintoma depresiboak, narriadura kognitiboa, eta usaimenaren gutxitzea bezalako nahasmen sentsorialak. SEM 
horien garrantzi klinikoa, pazientearen ezintasun funtzionalaren parte izatean, haien agerpen goiztiarrean eta ondoriozko gaixotasunaren biomarkatzaile posible izatean datza (1).

1. taula. PGaren sintoma ohikoenak.

\begin{tabular}{|l|l|}
\hline \multicolumn{1}{|c|}{ SINTOMA MOTOR KARDINALAK } & \multicolumn{1}{|c|}{ SINTOMA EZ MOTORRAK } \\
\hline Zurruntasuna & Idorreria \\
\hline Bradizinesia edo mugimenduen moteltzea & REM loaren jokabide-alterazioak \\
\hline \multirow{2}{*}{ Atsedeneko dardara } & $\begin{array}{l}\text { Disfuntzio disautonomikoa (hipotentsio } \\
\text { ortostatikoa, disfuntzio erektila, nahasmendu } \\
\text { urogenitalak) }\end{array}$ \\
\hline \multirow{2}{*}{ Ibileraren alterazioak } & Narriadura kognitiboa \\
\cline { 2 - 3 } & Hiposmia \\
\hline
\end{tabular}

PGaren etiologia ezezaguna izan arren, gaur-gaurkoz, gaixotasunaren garapenean eragina duten faktore anitz daudela uste da, ingurumen-faktoreak eta faktore genetiko eta epigenetikoak, batez ere. Beraz, aipatutako hiru faktore horiek batera eragiten dute zahartzaroan, neuroendekapenprozesua eta ondoriozko PGaren garapena martxan jarriaz $(26,27)$. Faktore ezberdinen ikerketak, eta horiek zenbait aldaera genetikoren testuinguruan sistema dopaminergiko nigroestriatalean duten inplikazio mekanismoa ezagutzeak, tratamendu eta gaixoen maneiu berrientzako ateak zabaltzen dizkigu. Adina da arrisku-faktore garrantzitsuena, eta zenbait ikerketa epidemiologikok traktu nigroestriataleko degenerazio dopaminergikoan parte hartzen duten beste zenbait faktore identifikatu dituzte (19); besteak beste inflamazioa (20) edota pestizidekiko edota kontaminatutako airearekiko esposizioa $(20,21)$, traumatismo kraneoentzefalikoen (TKE) aurrekarien presentzia $(22,23,24)$, eta zenbait dieta $(25)$, gizakiaren osasunarentzako eragin kaltegarriekin lotzen dira. Bestalde, neuronen babes-funtzioan parte hartzen duten zenbait faktore ere identifikatu dira, hala nola fruta, barazki, tabako, alkohol zein kafearen kontsumo moderatuak eta ariketa fisikoa, daukaten efektu antioxidatzaileagatik $(20,25)$. Horien inguruko ikerketa gehiago eta aurkikuntza adierazgarriagoak egiten diren heinean, ingurumen-faktoreak PGa garatzeko arriskuan duen inplikazioa hobeto ulertuko da.

PGdun pazienteen kopurua bikoiztu egin zen 1990 eta 2015 urteen artean, eta 6 milioi pazienteetara iritsi zen (13). Populazioaren zahartzea, bizi-itxaropenaren luzatzea, tabakoaren kontsumoaren beherakada eta industrializazioaren gorakada postulatzen dira gaixotasun honen prebalentziaren igoeraren arrazoi gisa (14,15). Herrialde industrializatuetako prebalentzia \%0,1-0,3 artean mantentzen da eta, adinak gora egin ahala, PGaren arriskua ere gorantz doa. Horrela, 60 urtetik gorako populazioan \% 1eko, eta 80 urtetik gorako pertsonetan \% 3ko prebalentzia estimatzen da (5). Meta-analisi batek zehaztu du PGk emakumezkoengan dituen intzidentzia eta prebalentzia gizonezkoengan duena baino zertxobait altuagoa direla $(16,17)$. 


\subsection{Sintoma ez motor ohikoenak Parkinson gaixotasunean}

- $\quad$ REM loaren jokabide-alterazioak (TCSR/REMJA): TCSRa PGan orain arte gehien aztertu izan den biomarkatzailea da (1). TCSRa nahaste neurologikoekin lotuta dagoela ikusi da, horien artean PGarekin, atrofia multisistemarekin $(7,9)$. Meta-analisi baten arabera TCSRa zutenen $\% 82,4 \mathrm{k}$ hamar urteko jarraipenean neuroendekapenezko gaixotasun bat garatu zuen. Horietako gehienek PGa (\% 43), eta Lewy gorpuzdun dementzia (LGD) beste gehiengo batek (\% 25) (4). Duela gutxiko ikerketen arabera, likido zefalorrakideoko (LZR) alfa-sinukleina mailak handiagoak dira TCSRa duten PGdun gaixoengan TCSR-rik ez dutenekin alderatuta $(10,11,12)$.

- Idorreria: Traktu gastrointestinaleko biopsia bidez 'in vivo' egindako zenbait ikerketak $(1,3)$ a-syn metaketa eta digestio-ehuneko neurotransmisoreen alterazioa egiaztatu zuten. Aurkikuntza hauek guztiek Braakek proposatutako eredua babesten dute, non PGdun pazienteetan digestio-ehuneko zein bagoaren nukleo dortsaleko $\alpha$-syn metaketak eta ondoriozko afekzio goiztiarrak zehazten zituzten. PGa duten pazienteen \% 24,6 eta \% 63 inguruk idorreria duela ikusi da (15). Ondorioz, idorreriak, PGaren fase prodromikoan biomarkatzaile gisa erabiltzeko sentsibilitate potentziala eduki lezake $(5,7)$.

- Depresioa: Depresioaren presentzia, TCSRarekin batera, PGaren biomarkatzaile prodromiko bezala ezartzen da, emaitza kognitibo zein motor okerragoak aurresanez. Duela gutxi, ikertzaile batzuek depresioa eta TCSRa gai zuriko zuntzen konexioen murrizketarekin erlazionatzen direla ikusi zuten (6).

\subsection{Parkinson gaixotasunaren biomarkatzaile klinikoak}

Osasuna edota gaixotasuna era objektiboan neurtzen laguntzen diguten aldagai edota balioak dira biomarkatzaileak. Biomarkatzaile horien adibide dira neuroriudi markatzaileak (DAT-SPECT eta metaiodobencilguanidina bidezko bihotz-gamagrafia), markatzaile biologikoak fluido desberdinetan adierazitakoak, adibidez, serumetan edo LZRetan, eta aipatutako markatzaile klinikoak, SEM esaterako. Hala ere, zenbait ikerketaren arabera, SMen agerpena etapa berantiar batean jazotzen dela ikusi da, PG motorraren garapena eragin duen prozesu fisiopatologikoa, SMen agerpena baino urte batzuk lehenago hasten baita $(5,6,7)$. SMak agertzerako, nerbio-sistemaren neurona dopaminergikoen galera \% 60< eta gorputz ildaskatuko dopamina (DA) $\% 80<$ murriztu dela ikusi da. Neuroirudi zein klinikan oinarritutako ebidentzia anitzek babesten dute idorreria edota loaren eta usaimenaren nahasteak, SMak baino zenbait urte lehenago ager litezkeela. SEMak PGaren zati integral gisa hartu eta ezagutzeak gaixotasuna ulertzeko modua aldatu du azken urteotan, diagnostiko goiztiarrago bat posible eginez. SEM horien hautemate goiztiarrak etorkizunean neuronen galera txikiagoko gaixoak identifikatu, eta, ondorioz, tratamendu eraginkorrago eta pazienteen maneiu egokiagoak gauzatzea ahalbidetuko liguke (8).

\subsection{Parkinson gaixotasunaren genetika}

Forma genetikoak PGaren kasuen \% 15en erantzule dira. 1997. urtean begiztatu zuten lehen aldiz parkinsonismoaren lehen aldaera genetikoa (SCNA). Aurkikuntza horrek PGaren etiologia ezezagunera gehiago gerturatzea ahalbidetu zuen, gaixotasuna ikusteko modua aldatuz, eta parkinson familiar batez hitz egiten hasiaz. Hortik aurrera, PGarekin erlazionatutako beste hainbat loci identifikatu dira (SNCA, PRKN, DJ-1, PINK, UCHL-1, LRRK2) $(26,27) .2004$. urtean euskal lantalde batek mutazio horietako bat aurkitu zuen, eta Gipuzkoako biztanlerian prebalentzia handia duela ohartu ziren. Hortik datorkio 'euskal mutazio' izena. Euskal mutazio hori R1441G, LRRK2 genean dago eta Dardarina izeneko proteina kodetzen du, "dardara" euskal hitza delarik $(26,27)$. R1441G mutazioa, 2004. urtean ezagutuz geroztik, beste 100 mutazio ezberdin aurkitu dira gene berean, nahiz eta soilik horietako $8 \mathrm{k}$ diruditen patologikoak $(26,27)$. Aurkikuntza horren oihartzuna geroztik egin izan diren publikazio anitzetan nabari da. Izan ere, PGaren fenotipo ohikoa duen paziente talde batean jatorri genetiko bat zehazteak zera erraztuko luke: kasuak aztertzea, gaixotasunaren fisiopatologia ezagutzea eta diagnostiko zein tratamendu goiztiarrak lortzeko markatzaile kliniko berrien detekzioa. 
2009. urtean, Ruiz Martinez eta kolaboratzaileek, lekuko forma genetikodun PG prebalentzia handiaz ohartzean, hautatutako bi udalerri horietako populazioa aztertzea erabaki zuten: Enfermedad de Parkinson por mutación vasca de la dardarina (LRRK2): estudio epidemiológico, clínico y genético $(26,27)$. Horretarako, Azkoitiako eta Azpeitiako (Gipuzkoa) herriak hautatu ziren, R1441G mutazioari lotutako PGaren kasu gehienak identifikatu ziren eskualdearen barruan baitzeuden bi udalerri hauek. Garaiko erroldako datuetatik, 500 pertsonaz osatutako lagin bat osatu zen ausaz $(26,27)$.

Adina PGaren garapenean zein progresioan eragin gehien duen faktorea dela jakinik, interesgarria iruditu zitzaigun 2009an aztertu zen lagina 10 urte geroago aztertzea, PGaren kasu gehiago aurkitzeko esperantzaz. Halaber, denbora pasatu ondoren SM zein SEM ezberdinen rola aztertzeak PGaren garapenerako arrisku-faktore edo markatzaile gisa joka dezaketen faktoreei buruz informazioa eman liezagukeelakoan geunden. 2019ko lan horretan, PGaren epidemiologiarako zein asoziatutako arrisku-faktoreenganako gerturatze bat egin nahi dugu, betiere, lagin txiki batek dituen mugak kontuan hartuz.

\section{Material eta metodoak}

Laginaren azterketa egiteko, 2009ko ikerketan parte hartu zuten 232 pertsonen informazio klinikoa aztertu da, Osabide programa informatikoaren bidez, aurretik aipatutako ezaugarrien bilaketa eginez. Argi ez zeuden kasuak baztertu dira eta PGaren diagnostikoa azterketa neurologikoaren bidez egin da.

Betiere, 15/1999 Izaera Pertsonaleko Datuen Babesaren Lege Organikoak ezarritako arauak betez jokatu da, bilaketa anonimoa eginez eta pazienteak identifikatzea ahalbidetuko luketen datuen presentziarik gabe,eta une oro paziente horien konfidentzialtasuna mantenduz.

Ikerketaren muga nagusia laginaren tamaina txikia izan da. Lortutako emaitzak testuinguru honetan soilik hartu beharko dira kontuan, ateratako ondorioen mugak onartuz.

\section{Emaitzak}

Eustatek 2018. urtean argitaratutako datuen arabera, Azkoitia eta Azpeitia udalerrietan 26.880 pertsona (11.964 Azkoitian eta 14.916 Azpeitian) bizi dira. Horietatik, 3.263 Azkoitian (\% 27,3) eta 4.358 Azpeitian (\% 29,2) 60 urtetik gorakoak dira. 2.269 (\% 18,96) eta 3.095 (\% 20,74), aldiz, 65 urtetik gorakoak. 2009. urteko zentsuko datuetan, populazio osoa 24.515 bizilagunekoa zen (10.701 Azkoitian eta 13.814 Azpeitian), aldiz, 65 urtetik gorakoak 4.301 ziren [1.983 (\% 18,53) Azkoitian eta 2.318 (\% 16,78) Azpeitian]. Beraz, lekuko prebalentzia kalkulatzeko, esan bezala, diagnostiko-kodeen bidezko bilaketa egin da udalerri horietan honako emaitzekin: Azkoitiko 11.964 bizilagunetatik 57 PG kasu eta Azpeitiko 14.916 bizilagunetik 47 kasu; beraz, Azkoitiko eta Azpeitiko prebalentzia osoa $\% 0,5$ eta $\% 0,32$ koa izan da hurrenez-hurren.

Aurrez 2009. urtean aztertutako lagin osotik $(n=232) 173$ parte-hartzaileren historia klinikoak lortu dira 2019. urtean. Gainerako 60 parte-hartzaileak ikerketatik kanpo gelditu dira, historia klinikoa ezin izan delako aztertu. Aurrez 2009. urtean aztertu zen laginetik, 5 kasutan duda klinikoak zeuden, baina 2019ko lagina aztertuz, inork ez du PGa garatu (1. irudia). 


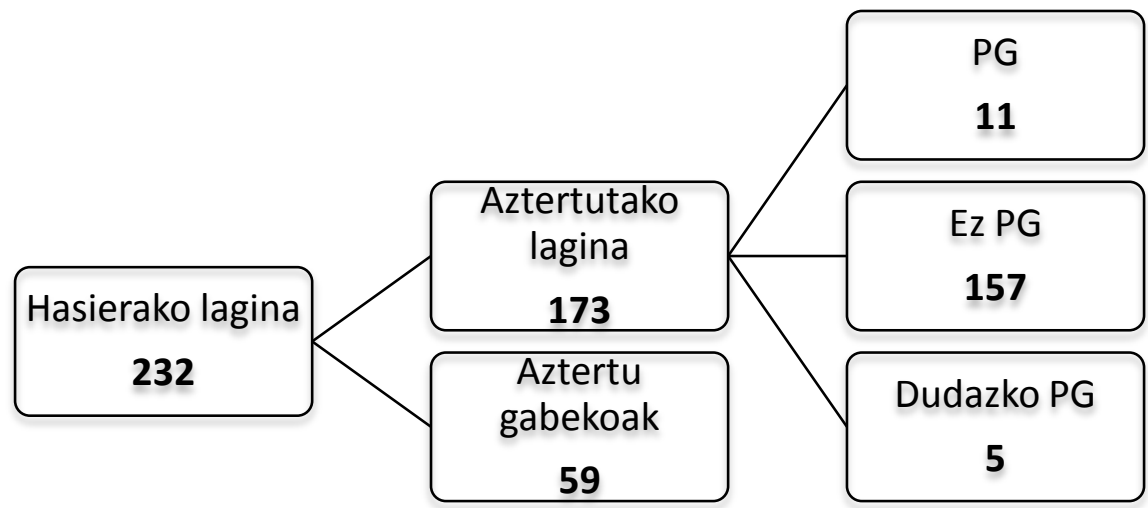

1. irudia. Laginaren esperotako hasierako distribuzioa eta ondoren aztertutakoa.

2009 eta 2019 ikerketetako laginen alderaketa (2. taula):

Lehenago 2009. urtean aztertutako lagina 232 parte-hartzailez osatuta zegoen, eta horietan 8 izan ziren PGarekin diagnostikatuak (\% 3,45). Hamar urteren ostean, 2019. urtean, lagina 173 partehartzailek osatzen dute (2009. urtean baino 60 gutxiago), eta 11 izan dira PG diagnostikoak (\% 6,36). Diagnostikatuen batez besteko adina, 2009. urtean 79,4 urtekoa izan zen; Aldiz, 2019. urtean 84,5 urtekoa izan da. Sexu-banaketari erreparatuz, 2009. urteko laginean 5 gizon eta 3 emakume zeuden (5/3). 2019. urteko laginean berriz, 6 ziren gizonezkoak eta 5 emakumezkoak (6/5). 2009. urtean 8 pazienteetatik hiruk idorreria zuten (\% 37,5), eta lauk 2019. urteko laginean (\% 36,4). TCSRaren presentziari dagokionez, 2009. urteko ikerketan 8 pazienteetatik lauk zuten alterazio hori $(\% 57,4)$, eta 2019. urtekoan 11 pazienteetatik bostek (45,5\%). Aurrekari familiarrak (AF) aztertuz, 2009. urteko ikerketan 4 pazientek AFak zituzten; horietatik hiruk lehen mailakoak zituzten, eta batek bigarren mailakoa. Bi mila eta hemeretziko gaixoen artean, 5 pazientek AFak izan dituzte, horietatik hiruk lehen mailakoak eta gainerako biek bigarren mailakoak. Beraz, diagnostiko berrien artean, bakar batek ditu AFak, eta zehazki bigarren mailakoak.

2. taula: 2009 eta 2019 urteetako laginen konparaketa PGaz diagnostikatutako taldean.

\begin{tabular}{|l|c|c|}
\hline & $\mathbf{2 0 0 9}$ & $\mathbf{2 0 1 9}$ \\
\hline Aztertutako lagina & 232 & 173 \\
\hline PG kopurua & 8 & $\mathbf{1 1}$ \\
\hline Estimatutako prebalentzia & $\% 3,45$ & $\mathbf{\%} 6,35$ \\
\hline PGa dutenen batez besteko adina & $79,4(62-92)$ & $84,5(68-101)$ \\
\hline $\begin{array}{l}\text { PG sexu-banaketa } \\
\text { (gizonezko/emakumezko) }\end{array}$ & $5 / 3$ & $6 / 5$ \\
\hline TCSR PGan & $4(\% 57,4)$ & $\mathbf{5}(\% 45,5)$ \\
\hline Idorreria PGan & $3(\% 42,8)$ & $4(\% 36,4)$ \\
\hline $\begin{array}{l}\text { A. Familiarrak (AF): } \\
\text { 1. mailakoa }\end{array}$ & $4(\% 57,1)$ & $5(\% 45,4)$ \\
\hline - 2. mailakoa & 3 & 3 \\
\hline TKE PGan & $3(\% 42,8)$ & $3(\% 27)$ \\
\hline Tabakoa: & 0 & 0 \\
\hline Aktiboa & $4(\% 57,1)$ & $4(\% 36,4)$ \\
\hline $\begin{array}{l}\text { Ohia } \\
\text { Pasiboa }\end{array}$ & 1 & $2(\% 18,2)$ \\
\hline Kafea PGan & $3(\% 42,8)$ & $3(\% 27,3)$ \\
\hline R114G mutazioa & $2(\% 28,5)$ & $2(\% 18,2)$ \\
\hline Jatorri euskalduna & $6(\% 85,7)$ & $8(\% 80)$ \\
\hline
\end{tabular}


Bestelako faktoreak aztertzean, babesle gisa jo izan den tabako- zein kafe-kontsumoari erreparatuz, ez dago erretzaile aktiborik gaixoen artean. Zortzi gaixotan 4 erretzaile ohiak ziren 2009. urtean, eta bat pasiboa. Erretzaile pasibo bat gehiago dago 2019. urtean, gainerako bi diagnostiko berriek ez baitute tabakoarekiko erlaziorik adierazi. Kafearen kontsumoari dagokionez, bai 2009. eta bai 2019. urtean, pazienteen artean 3 soilik ziren kontsumitzaile. Azken hamar urteetan diagnostikatu diren hiru kasuen artean ez dago kafe-kontsumitzailerik. NOx, NO2 edota PM10/2.5 gisako toxikoekiko kontaktuari dagokionez, batek eduki du kontaktua (\% 9). R1441G mutazioaren eramaile direnen inguruan, diagnostiko berrien artean, inor ere ez da mutazioaren eramaile. Beraz, talde horretan mutazioaren eramaile direnen kopurua berdin mantentzen da $(n=2) .2009$ urtean 6 pazientek jatorri euskalduna zuten (\% 85,7); ordea, 2019. urtean zortzik zuten (\% 80). Hiru pazientek egin zuten lan lantegi batean 2009. zein 2019. urtean, eta gainerakoek etxeko edota bulegoko lana izan zuten.

Lagin osoaren $(n=173)$ azterketari erreparatuz, 2009ko ikerketan, zalantzazko parkinsonismo gisa sailkatutako kasuen artean,, inork ere ez du hamar urteren ostean PGa garatu. Aztertutako 173 parte-hartzaileko laginetik, 11k PGaren diagnostikorako irizpideak betetzen dituzte, 162 partehartzaileetan PG diagnostikoa baztertu da hasieratik. Hasierako laginean dudazko kasu gisa sailkatutako bostek PGa ez den bestelako gaixotasun neuroendekapenezkoren bat garatu dute. Egungo 11 PG diagnostikoetatik, 8 2009. urtean diagnostikatuta zeuden jada. Beraz, 3 kasu berri aurkitu dira egungo ikerketan, hamar urteren ostean. (2. irudia).

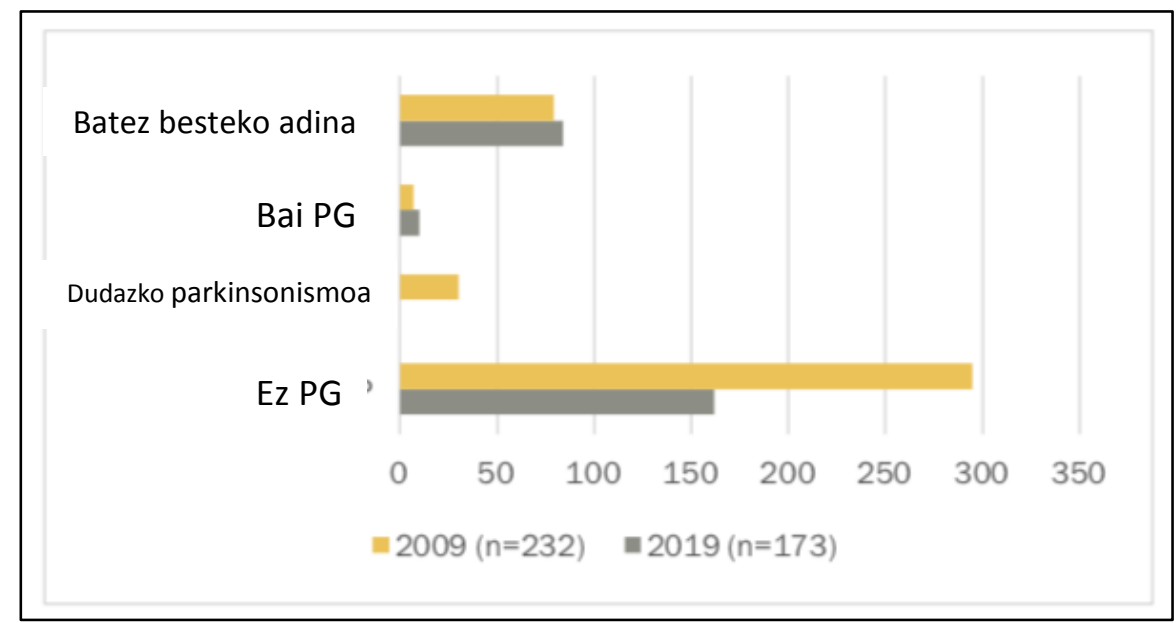

2. irudia. Laginaren banaketa 2009 eta 2019 urteetan.

2009. urtean idorreria zuten 57 parte-hartzaileetan lauk $(\% 7,1)$ PGa dute gaur; TCSRa zuten 8ren artean bostek (\% 62,5); TKE aurrekariren bat zutela zioten 15etan hiruk (\% 20); AFak zituzten 30etan bik, eta tabako- / kafe-kontsumitzaile ziren 76 parte-hartzaileetan hiruk dute PGa egun (3. taula, 3. irudia).

3. taula: 2009ko laginetik PGa garatu duten parte-hartzaile kopurua beren arrisku-faktoreekiko erlazioan.

\begin{tabular}{|l|c|cc|}
\hline Arrisku-faktorea & $\mathbf{2 0 0 9}$ & PGa 2019 urtean & $\%$ \\
\hline Idorreria & 57 & 3 & $\% 7,10$ \\
\hline TCREM & 8 & 5 & $\% 62,50$ \\
\hline AF & 30 & 2 & $\% 6,6$ \\
\hline TKE & 15 & 3 & $\% 20$ \\
\hline
\end{tabular}




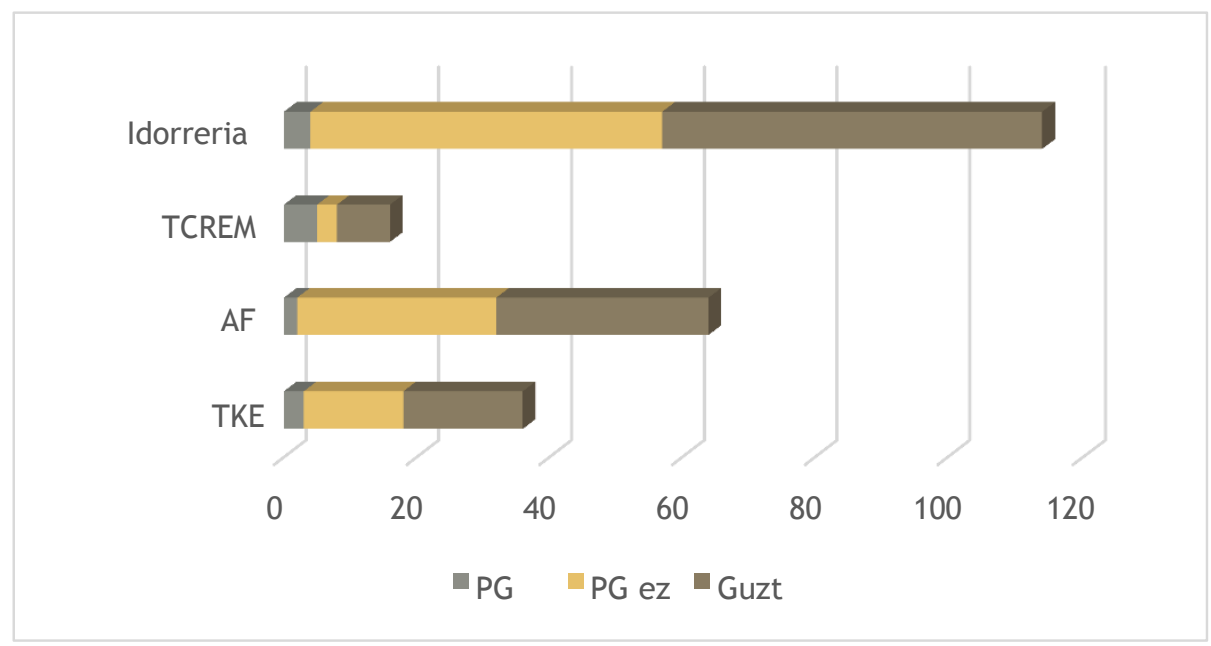

3. irudia. 2009. urtean aztertutako ezaugarrien irudikapena 2019. urtean.

PGa dutenen ( $n=11$ ) taldearen ezaugarriei dagokienez, (4-5. taulak), ), hirurek dute idorreria (\% 37), bostek TCSRa (\% 50), hirurek TKE aurrekariak $(\% 37,5)$ eta bostek AFak (\%50), azken horietatik hiruk, lehen mailakoak, eta gainerako biek, bigarren mailakoak. PGa duen taldearen batez besteko adina 84,5 urtekoa da, gazteenak 68 urte ditu eta zaharrenak 101. Diagnostikoa egiten den batez besteko adina 71,5 urtekoa da; R1441G mutazioaren eramaileen artean 70,5 urte, eta mutazioa ez dutenen artean 73,1 urte. Jatorriari dagokionez, aldiz, 8 euskaldunak dira.

Datuak horrela, ikerketan parte hartu duten guztien artean kalkulatutako PGaren prebalentzia $\%$ 5,8koa da (4. taula).

4. taula. 2009. urtean aztertutako ezaugarrien irudikapena, gaur egungo laginean (2019).

\begin{tabular}{|l|c|cc|}
\hline Arrisku-faktoreak & EZ & BAI & $\%$ \\
\hline Idorreria & 8 & 3 & $\% 37,5$ \\
\hline TCREM & 6 & 5 & $\% 50$ \\
\hline AF & 6 & 5 & $\% 50$ \\
\hline TKE & 8 & 3 & $\% 37, \%$ \\
\hline
\end{tabular}


5. taula. PGdun pazienteen azterketa 2019. urtean. D (Dardara), D-Z (DardaraZurruntasuna), M (Mistoa), + (Bai), -(ez), E (Idorreria), REMJA (REM loaren jokabidealterazioak), $\mathrm{A}$ (erretzaile aktiboa), $\mathrm{P}$ (erretzaile pasiboa).

\begin{tabular}{|c|c|c|c|c|c|c|c|c|c|}
\hline Pazientea & Adina & Fenotipoa & SEM & Ogibidea & TKE & Tabakoa & Kafea & Toxikoa & Gen \\
\hline 1 & 64 & $\mathrm{D}$ & 1 & Etxea & - & Ex & - & - & $+R$ \\
\hline 2 & 56 & D & - & Fabrika & - & Ex & + & - & $+R$ \\
\hline 3 & 82 & $D-Z$ & TCSR & Fabrika & + & Ex & + & + & - \\
\hline 4 & 67 & D & $\begin{array}{c}\text { I, } \\
\text { TCSR } \\
\text { I, }\end{array}$ & Bulegoa & - & $P$ & - & - & - \\
\hline 5 & 65 & $\begin{array}{l}\mathrm{D} \\
\dot{i}\end{array}$ & $\begin{array}{c}\text { TCSR } \\
- \\
\end{array}$ & $\begin{array}{l}\text { Etxea } \\
\text { Fabrika }\end{array}$ & - & - & - & - & - \\
\hline $\begin{array}{l}6 \\
7\end{array}$ & $\dot{c}$ & D-Z & - & Bulegoa & - & - & - & - & - \\
\hline 8 & $\begin{array}{l}78 \\
70\end{array}$ & $M$ & TCSR & Etxea & - & Ex & - & + & - \\
\hline 9 & 80 & $\dot{c}$ & $\mathrm{I}$, & Etxea & - & - & + & + & - \\
\hline & & & TCSR & & - & - & - & - & - \\
\hline 10 & 83 & $\dot{c}$ & - & Etxea & - & $P$ & - & - & - \\
\hline 11 & 60 & $\dot{c}$ & - & Byuegoa & - & - & - & - & - \\
\hline GUZTIRA & & $\begin{array}{c}\mathrm{D}: 4 \\
\mathrm{D}- \\
\mathrm{Z}: 2 \\
\mathrm{M}: 1\end{array}$ & $\begin{array}{c}41 \\
5 T C S R \\
\text { EM }\end{array}$ & $\begin{array}{c}5 \mathrm{E} 3 \mathrm{O} \\
2 \mathrm{~F}\end{array}$ & 1 & $\mathrm{OA}$ & 3 & 3 & $2 R$ \\
\hline
\end{tabular}

Honako hauek dira hiru diagnostiko berrien ezaugarriak: lehenengo pazientea 85 urteko emakume bat da, jatorriz euskalduna, 2009. urtean idorreriarik ez zuena, baina ez du TCSRa pairatzen eta ez du AFrik. Bigarrena 68 urteko gizon bat da, jatorriz euskalduna; ez zuen idorreriarik, ezta TCSR-rik ere, baina AFak dauzka. Azkenik, hirugarren pazientea 88 urteko emakume bat da, jatorriz ez euskalduna, eta 2009. urteko ikerketan ez zuen ez aurrekari familiarrik, ez idorreriarik ezta TCSR-rik ere.

\section{Eztabaida}

Azkoitiko eta Azpeitiko populazioak gorakada egin du azken 10 urteotan. Horrekin batera, Azpeitian, populazioaren zaharkitzea nabarmendu da, baina horrek ez du bi udalerrietako kasuen proportzioan eraginik izan.

Inguru horretan aztertutako lagina orokorrean nahiko homogeneo mantendu da 10 urteetan, PGaren diagnostikoen gorakadarekin batera. Beraz, aipatu bezala, zentzuzkoa denez, 10 urteren ostean, laginaren batez besteko adina altuago da (84,5 urte, 2009ko 79,4 urteren aurrean), eta faktore horrek PGaren diagnostikoen gorakada ekarri beharko luke, errealitatean gertatu den eta behatu ahal izan den bezala. Zahartzaroan, mekanismo orekatzaileen faltak (mitokondrien oxigenazioa, ubikitinizazioa, proteasoma bidezko proteolisia eta lisosoma bidezko autofagia) neuroendekapenprozesua indartzen du. Hortik, adinak duen garrantzia neuroendekapen-prozesuan (28). Nahiz eta 
diagnostiko berrien kopurua txikia izan, laginaren PGaren prebalentziak 65 urtetik gorako populazioarentzat estimatutako ohiko prebalentziak gainditzen ditu. Kontuan izan behar da laginaren tamaina txikia dela, baita diagnostikoak egiteko erabili den metodoaren mugak eta positibo faltsuak izateko arriskua ere. Sexuen banaketari buruz, 2009. zein 2019. urtean, gizonezko gehiago diagnostikatu dira. Datu horren aurka, beste autore batzuek PGaren prebalentzia orokorra emakumezkoetan handiagoa dela azpimarratzen dute, desberdintasuna txikia bada ere $(16,17)$.

Sintoma motorrak: 2009. urteko esplorazio neurologikoan behatutako PGaren zeinu isolatuen presentziak ez du gaitza garatzeko arrisku handiagorik eragin 10 urte geroago. Izan ere, eskura izan ditugun zalantzazko parkinsonismo gisa sailkatutako 5 gizabanakoen artean inork ere ez ditu 10 urteren ostean PGaren diagnostikorako irizpideak bete. Emaitza horiek bat datoz PGaren irizpide klinikoekin (bradizinesia eta gutxienez honako hauetako bat: giharren gogortasuna, atsedeneko dardara, edo/eta ikusmenaren, orekaren, garuntxoaren edota propriozepzioaren nahasmenen ondoriozko ez den jarreraren desoreka; Brain Banken irizpideak), non sintoma horiek aldi berean agertzea beharrezkotzat jotzen duten diagnostikoa egiteko. Ikerketa honetan ikusten den bezala, PGaren sintoma bereizgarriak banaka agertzeak ez du gaitza garatzeko arriskua handiagoa denik esan nahi. Zalantzazko parkinsonismoaren kasuak beste eritasun neuroendekapenezkoetan suertatu dira (31).

\section{Sintoma ez motorrak:}

TCSR/REMJA: 2009. urteko galdeketa gidatuan, TCSRa zuten 8 gizabanakoen artean 4 izan dira PGaz diagnostikatuak 2019. urtean. TCSRaren agerpena PGa garatzeko arrisku-faktorea izan liteke, nahaste hori zuten gizabanako urrietan gehienek gaixotasuna izango baitute. Beraz, TCSR kontuan hartzeko sintoma bat da. Horrekin, gure datuek zenbait artikulutakoak baieztatzen dituzte. Frogek esaten dutenez, TCSRa duten gizabanakoek neuroendekapen-eritasun bat garatzeko arriskua epe luzera $\% 90$ etik gorakoa da $(28,29)$. Gainera horren presentzia PG azpimota agresiboagoarekin, sintoma depresiboekin eta narriadura kognitiboarekin erlazionatzen da $(6,11)$. TCSRaren inguruko azterketa galdeketa gidatu baten bidez egin zen, eta horren diagnostikorako azterketa polisomnografikorik ez izateak okerreko ondorioak izateko arriskua handitzen du. Hala ere, emaitzak kontuan hartzekoak dira eta bat datoz orain arte esan eta ikertu izan denarekin.

Idorreria, PGaren biomarkatzaile kliniko gisa: Idorreria, 2019ko lagin osoaren \% 40k du. 2009. urteko lagina behatuz, idorreria zuten 57 gizabanakoetan lauk izan dute PGa 2019an eta, horietan, diagnosi berrien artean bkr batek soilik. Ondorioz, nahiz eta idorreria SEMen biomarkatzaile goiztiar garrantzitsua izan, lan honetan ez da faktore erabakigarria izan eta ez du PGaren garapena aurresan. Hala ere, aurretik aipatu den bezala, lagina txikia da eta, beraz, ondorio horiek arretaz aztertu behar dira.

Faktore genetiko eta ingurumen-faktoreak atalean ez dira ondorio esanguratsuak lortu, laginak bereziki duen errepresentazio eskasagatik. Horretarako, lortutako datuez gain, artikulu zientifikoetatik eskuratutako informazioaz baliatu gara.

\section{Faktore genetikoak:}

- LRRK2 genearen R1441G mutazioari dagokionez, nahiz eta 2009. urteko ikerketa egiteko arrazoia udalerri hauetan R1441G mutazioari lotutako PGaren prebalentzia handia izan, 2019. urtean diagnostikatu diren PG kasu berrien artean inork ere ez du mutaziorik izan. 2019ko lagin osoan, mutazioaren eramaileen erdiek eritasuna dute (4/2). Gainerako bi eramaileek ez dute gaixotasuna garatu 10 urte pasa ondoren. Orain arteko frogen arabera, R1441G mutazioaren penetrantzia edo sarkortasuna \%83koa da laurogei urtetik aurrerakoetan; lan honetako emaitzetan, aldiz, ez da horrelakorik aurkitu (30). Laginean ikusten den bezala, nahiz eta sarkortasuna handia izan, ez da guztizkoa, eramaile diren bi kasuk ez baitute eritasuna garatu denbora pasa ahala. Beraz, faktore genetikoa garrantzitsua da, baina ez da nahikoa.

- AFen presentziari dagokionez, AFak zituzten 30 parte-hartzaileetan bik garatu dute PGa (\% 6.6). Aurretik aipatu den bezala, 10 urteko ikerketa honetan, AFen presentzia ez da esanguratsua izan 
PGa garatzeko arriskuari dagokionez, oraindik zehaztu gabeko sarkortasun txikiko mutazioen eramaile izateagatik, edota pertsonak berak izan ditzakeen babes-faktoreen presentziarengatik.

\section{Ingurumen-faktoreak}

Ingurumen-faktoreek PGan duten eragina aztertzea ez da erraza, toxiko motek, esposizio-denborek edota erabilitako segurtasun-metodoek eragina baitute.

- PGa duten 11tik soilik 3k izan zuten fabrikako lana, eta, beraz, ziurrenik ingurugiro toxiko batekiko esposizioa izan zutela suposatu liteke.

- TKE aurrekariei dagokienez, 2009. urtean TKE aurrekaria zuten eta ondoren PGa garatu duten gizabanakoen kopurua garrantzitsua izan da. Hauek, kontuan hartzeko emaitzak dira, eta orain arte ikertutakoarekin bat datoz. Izan ere, hainbat ikerketatan aztertu izan da mikrotraumatismoek neuroendekapenezko prozesuan duten garrantzia.

- Tabako- / kafe-kontsumoari dagokionez: laginaren tamainak ezinezkoa egiten du ondorio esanguratsuak ateratzea, ez baitago erretzaile aktiboa den pertsonarik gaixoen artean, eta soilik hiruk kontsumitzen baitute kafea. Tamaina handiagoa duten laginen eta epe luzeagoko jarraipena duten ikerketak behar dira faktore hauen eragina aztertzeko.

\section{Ondorioak}

Lan honen mugak kontuan hartuta ere, hamar urte pasa ondoren aztertutako laginean PGaren diagnostikoen gorakada behatu da, beraz, adina PGa garatzeko arrisku-faktore garrantzitsua da.

10 urte igaro ondoren egindako analisian, TCSRak PGaren garapenean duen eraginari buruz, orain arteko ikerketetan aipatu izan denarekin erlazio estua dago, eta, beraz, horren jarraipenak duen garrantzia baieztatzen da, PGa garatzeko arriskua aurreikusteko eta biomarkatzaile gisa jokatzeko duen gaitasunarengatik.

TKEren aurrekaria, nahiko prebalentzia handian azaldu da lagin horretan, eta, idorreria, orain arteko ikerketetan esan den ez bezala, ez da faktore adierazgarria izan.

\section{Erreferentzia bibliografikoak}

1. Cuenca L, Gil-Martinez AL, Cano-Fernandez L, Sanchez-Rodrigo C, Estrada C, Fernandez-Villalba E, Herrero MT. Parkinson's disease: a short story of 200 years. Histol Histopathol. 2019;34(6):573-591.

2. Son SJ, Kim M, Park H. Imaging analysis of Parkinson's disease patients using SPECT and tractography. Sci Rep. 2016; 30;6: 38070..

3. Scheperjans F, Derkinderen P, Borghammer P. The Gut and Parkinson's Disease: Hype or Hope? J Parkinsons Dis. 2018;8 (s1): S31-S39.

4. Wintraub D, Comella CL, Hom S. Parkinson's Dlsease-Part1: Pathophysiology, symptms, burden, diagnosis, and assesment. Am J Manag Care. 2008 ;14(2 Suppl): S40-48

5. Ascherio A, Schwarzschild MA. The epidemiology of Parkinson's disease: risk factors and prevention. Lancet Neurol. 2016;15(12):1257-1272

6. Ghazi Sherbaf F, Rostam Abadi Y, Mojtahed Zadeh M, Ashraf-Ganjouei A, Sanjari Moghaddam H, Aarabi $\mathrm{MH}$. Microstructural Changes in Patients With Parkinson's Disease Comorbid With REM Sleep Behaviour Disorder and Depressive Symptoms. Front Neurol. 2018; 9:441

7. Savica R, Rocca WA, Ahlskog JE. When does Parkinson disease start? Arch Neurol. 2010; 67(7):798-801

8. Prange, S., Danaila, T., Laurencin, C., Caire, C., Elise, E., Merle, H., Broussolle, E., Maucort-Boulch, D., Thobois, S. Age and time course of longterm motor and nonmotor complications in Parkinson disease. American academy of Neurology, 92 (2), e148-e160..

9. Barone DA, Henchcliffe C. Rapid eye movement sleep behavior disorder and the link to alphasynucleinopathies. Clin Neurophysiol. 2018;129(8):1551-1564.

10. Liguori C, Paoletti FP, Placidi F, Ruffini R, Sancesario GM, Eusebi P, Mercuri NB, Parnetti L. CSF Biomarkers for Early Diagnosis of Synucleinopathies: Focus on Idiopathic RBD. Curr Neurol Neurosci Rep. 2019;19(2):3. 
11. Pagano G, De Micco R, Yousaf T, Wilson H, Chandra A, Politis M. REM behavior disorder predicts motor progression and cognitive decline in Parkinson disease. Neurology. 2018;91(10):e894-e905.

12. Kim R, Lee J, Kim HJ, Kim A, Jang M, Jeon B, Kang UJ. CSF $\beta$-amyloid42 and risk of freezing of gait in early Parkinson disease. Neurology. 2019;92(1):e40-e47.

13. Stirpe $P$, Hoffman $M$, Badiali D, Colosimo C. Constipation: an emerging risk factor for Parkinson's disease? Eur J Neurol. 2016;23(11):1606-1613

14. Dorsey ER, Sherer T, Okun MS, Bloem BR. The Emerging Evidence of the Parkinson Pandemic. J Parkinsons Dis. 2018;8(s1):S3-S8

15. Vlaar T, Kab S, Schwaab Y, Fréry N, Elbaz A, Moisan F. Association of Parkinson's disease with industry sectors: a French nationwide incidence study. Eur J Epidemiol. 2018; 33(11):1101-1111

16. Goetz CG, Chmura TA, Lanska DJ. The history of Parkinson's disease. Part 2 of the MSD-sponsored History of Movement Disorders exhibit, Barcelona, June 2000. Mov Disord. 2001 ; 16 :156-61

17. Gibb WR, Lees AJ. The relevance of the Lewy body to the pathogenesis of idiopathic Parkinson's disease. J Neurol Neurosurg Psychiatry. 1988;51(6):745-52

18. Van Den Eeden SK, Tanner CM, Bernstein AL, Fross RD, Leimpeter A, Bloch DA, Nelson LM. Incidence of Parkinson's disease: variation by age, gender, and race/ethnicity. Am J Epidemiol. 2003;157(11):1015-22.

19. Lee A, Gilbert RM. Epidemiology of Parkinson Disease. Neurol Clin. 2016;34(4):955-965

20. Palacios N. Air pollution and Parkinson's disease - evidence and future directions. Rev Environ Health. 2017;32(4):303-313

21. Elbaz A, Clavel J, Rathouz PJ, Moisan F, Galanaud JP, Delemotte B, Alpérovitch, A, Tzourio C. Professional exposure to pesticides and Parkinson disease. Ann Neurol. 2009;66(4):494-5041

22. Daglas M, Adlard PA. The Involvement of Iron in Traumatic Brain Injury and Neurodegenerative Disease. Front Neurosci. 2018; 12:981

23. Huang $\mathrm{CH}$, Lin CW, Lee YC, Huang CY, Huang RY, Tai YC, Wang KW, Yang SN, Sun YT, Wang HK. Is traumatic brain injury a risk factor for neurodegeneration? A meta-analysis of population-based studies. BMC Neurol. 2018;18(1):184

24. Bae YH, Joo H, Bae J, Hyeon SJ, Her S, Ko E, Choi HG, Ryu H, Hur EM, Bu Y, Lee BD. Brain injury induces HIF$1 \alpha$-dependent transcriptional activation of LRRK2 that exacerbates brain damage. Cell Death Dis. $2018 \mathrm{Nov}$ 12;9(11):1125.

25. Munoz DG, Fujioka S. Caffeine and Parkinson disease: A possible diagnostic and pathogenic breakthrough. Neurology. 2018;90(5):205-206.

26. Ruiz-Martinez J. Enfermedad de Parkinson por mutación vasca de la dardarina (LRRK2): estudio epidemiológico, clínico y genético [Internet].[Donostia-San Sebastian]: Universidad del País Vasco = Euskal Herriko Unibertsitatea; 2012 [Kontsulta: 2020-01-23]. 147 or. Eskuragarri: http://hdl.handle.net/10810/17748.

27. Ruiz Martinez J., Soria I., Gorostidi A., Estanga A., Bergareche Al, Etxart M., Emparanza J., Lopez de Munain A., Geyenechea E., Martí Masso JF. Prevalence of LRRK2 mutations in a population study in two selected rural basque villages (Spain). 2011Hindle JV. Ageing, neurodegeneration and Parkinson's disease. Age Ageing. 2010Mar;39(2):156-61.

28. Hindle JV. Ageing, neurodegeneration and Parkinson's disease. Age Ageing. 2010;39(2):156-61.

29. Galbiati A, Verga L, Giora E, Zucconi M, Ferini-Strambi L. The risk of neurodegeneration in REM sleep behavior disorder: A systematic review and meta-analysis of longitudinal studies. Sleep Med Rev. 2019; 43:37-46.

30. Ruiz-Martínez J, Gorostidi A, Ibañez B, Alzualde A, Otaegui D, Moreno F, López de Munain A, Bergareche A, Gómez-Esteban JC, Martí Massó JF. Penetrance in Parkinson's disease related to the LRRK2 R1441G mutation in the Basque country (Spain). Mov Disord. 2010;25(14):2340-5.

31. Gibb WR, Lees AJ. The relevance of the Lewy body to the pathogenesis of idiopathic Parkinson's disease. Journal of Neurology, Neurosurgery \& Psychiatry 1988;51:745-752.

\section{Esker onak}

Eskerrik asko ikerketa lan honen zuzendari eta oinarri izan diren Ruiz Martínez eta Olasagasti doktoreei. Baita lan hau gauzatzeko ezinbesteko izan den diagnostikoen bilaketan lagundu duen Javier Basterrecheari ere.

\section{Esker onak parte hartzaileei}

Eskerrak 2009 urteko ikerketako kide izan ziren Azkoitia eta Azpeitiako parte hartzaile guztiei, beraien esker eta gogo onak posible egin baitu gaur egungo ikerketa honen burutzea. 